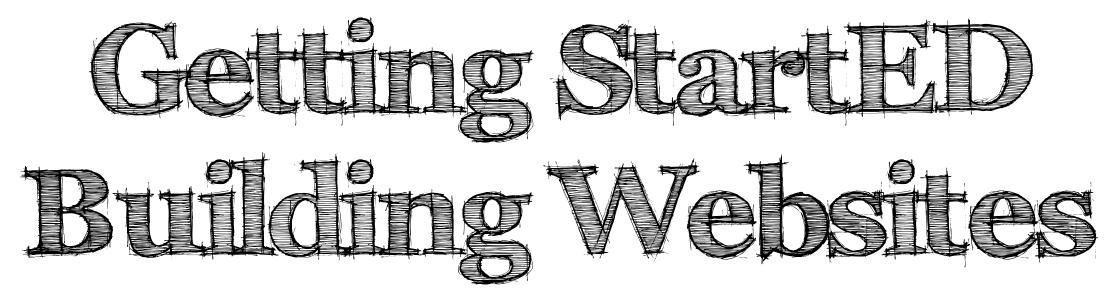

Alexander Dawson

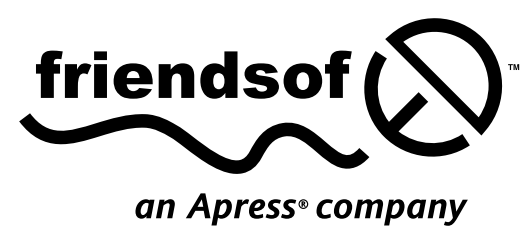




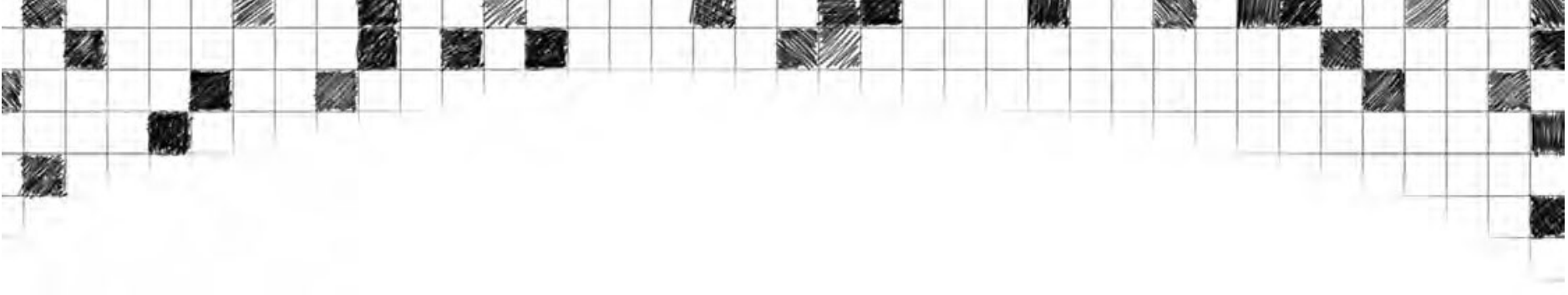

\section{GETTING STARTED BUILDING WEBSITES}

\section{Copyright @ 2009 by Alexander Dawson}

All rights reserved. No part of this work may be reproduced or transmitted in any form or by any means, electronic or mechanical, including photocopying, recording, or by any information storage or retrieval system, without the prior written permission of the copyright owner and the publisher.

ISBN-13 (pbk): 978-1-4302-2517-1

ISBN-13 (electronic): 978-1-4302-2518-8

Printed and bound in the United States of America 987654321

Trademarked names may appear in this book. Rather than use a trademark symbol with every occurrence of a trademarked name, we use the names only in an editorial fashion and to the benefit of the trademark owner, with no intention of infringement of the trademark.

Distributed to the book trade worldwide by Springer-Verlag New York, Inc., 233 Spring Street, 6th Floor, New York, NY 10013. Phone 1-800-SPRINGER, fax 201-348-4505, e-mail orders-ny@springer-sbm.com, or visit WWW. springeronline.com.

For information on translations, please e-mail info@apress.com, or visit www.apress.com.

Apress and friends of ED books may be purchased in bulk for academic, corporate, or promotional use. eBook versions and licenses are also available for most titles. For more information, reference our Special Bulk Sales-eBook Licensing web page at http://www.apress.com/info/bulksales.

The information in this book is distributed on an "as is" basis, without warranty. Although every precaution has been taken in the preparation of this work, neither the author(s) nor Apress shall have any liability to any person or entity with respect to any loss or damage caused or alleged to be caused directly or indirectly by the information contained in this work.

\section{Credits}

\section{President and Publisher: Paul Manning \\ Lead Editor: \\ Ben Renow-Clarke \\ Technical Reviewer: \\ Kristian Beasley \\ Editorial Board:}

Clay Andres, Steve Anglin, Mark Beckner, Ewan

Buckingham, Gary Cornell, Jonathan Gennick, Michelle

Lowman, Matthew Moodie, Jeffrey Pepper, Frank

Pohlmann, Ben Renow-Clarke, Dominic Shakeshaft, Matt

Wade, Tom Welsh

\section{Coordinating Editor: \\ Kelly Moritz}

\section{Copy Editor:}

Patrick Meader and Heather Lang

\section{Compositors:}

MacPS, LLC

Indexers:

BIM Indexing \& Proofreading Services

Artist:

April Milne

Cover Designer:

Kurt Krames 
For the long-suffering professionals who work tirelessly to make the Web a better place, especially those individuals who continue to strive for a more accessible and standardscompliant Internet. 


\section{Conitenils ar a GHance}

Contents at a Glance ........................................................... iv

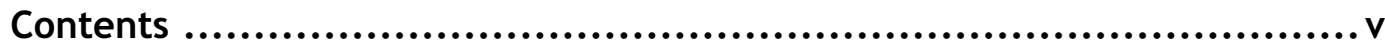

About the Author.............................................................. xi

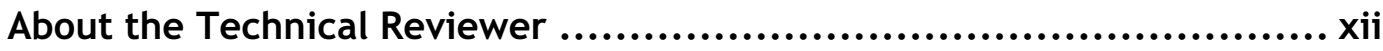

Acknowledgments ........................................................ xiii

Introduction .......................................................... xv

Chapter 1: What Kind of Website Should I Make? ............................1

Chapter 2: How Do I Write Good Content? ................................... 65

Chapter 3: How Should I Start Coding My Site? ........................... 115

Chapter 4: What About Web Hosting?...................................... 195

Chapter 5: How Can I Style My Website? ................................. 227

Chapter 6: How Can I Use Images and Media? ............................. 313

Chapter 7: What If Something Goes Wrong? .............................. 351

Chapter 8: How Can I Add Interactivity? ................................. 407

Chapter 9: How Can My Website Be Improved? ........................... 465

Chapter 10: How Can I Get More Visitors? ................................. 529

Appendix A: The Ten Commandments for Websites ..................... 591

Appendix B: Additional Materials ....................................... 597

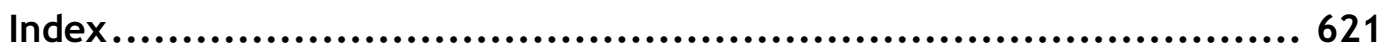




\section{Conitentits}

Contents at a Glance ........................................................... iv

Contents ....................................................................

About the Author................................................................xi

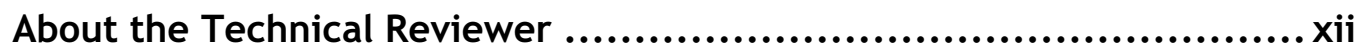

Acknowledgments ........................................................ viii

Introduction ........................................................... xv

Chapter 1: What Kind of Website Should I Make? .......................... 1

Who Are You? ................................................... 1

Your Inner Processes ......................................................... 2

What Type of Site? ...................................................... 6

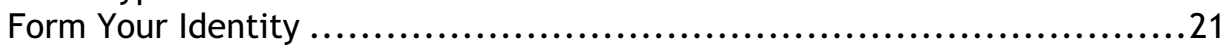

Inspiration for the Masses........................................ 24

Sources of Inspiration....................................................25

Idea Development Techniques ............................................ 30

Information Architecture ............................................... 49

Layout ................................................................... 50

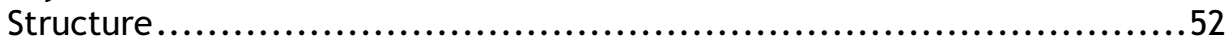

The Vision Quest.................................................... 57

Summary....................................................... 61

Chapter 2: How Do I Write Good Content? ...................................6 65

Content Is King! ....................................................... 65

What is Content?.........................................................

Information Design ................................................. 72

Website Writing........................................................ 95

The Basics of Writing ........................................... 98

How to Write Effectively ..............................................98

Conclusion .............................................................. 104

Cover Your Ass(ets)! .................................................... 106

Summary......................................................... 113

Chapter 3: How Should I Start Coding My Site? ........................... 115

Back to Basics.................................................... 116

Under the Hood .................................................... 116

Your Checklist......................................................... 130

Getting StartED ............................................. 136

Your First Web Page....................................................... 137

From Content to Context ....................................... 140

Placing Your Content ................................................. 140

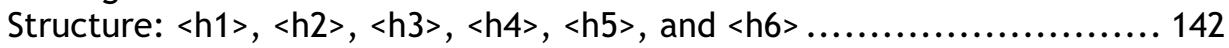




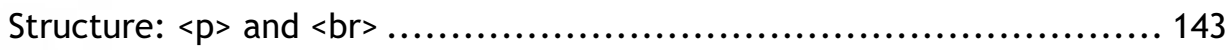

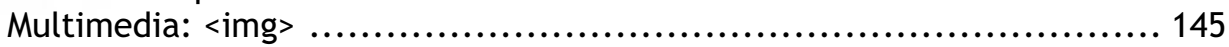

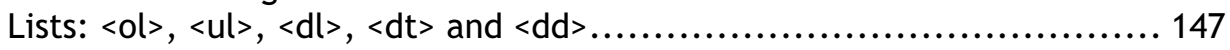

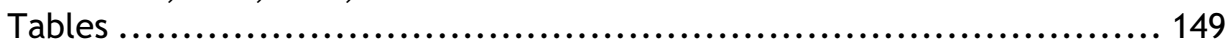

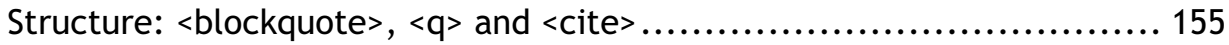

Multimedia: <object>, <embed>, <noembed>, and <param> .............. 156

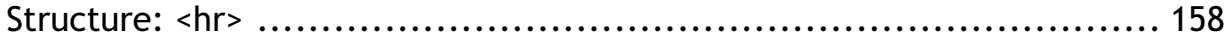

Multimedia: <map > and <area> ....................................... 159

Structure: <address> ................................................... 160

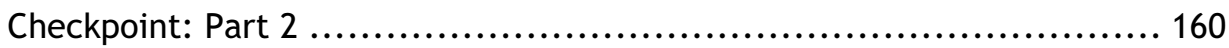

Enhancing Content ............................................. 162

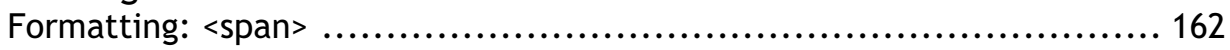

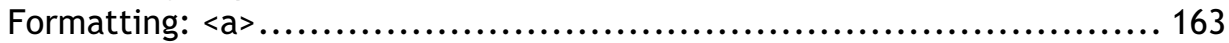

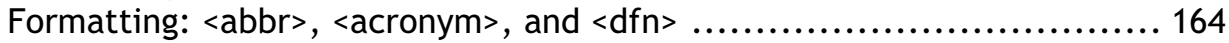

Formatting: $\langle\mathrm{b}\rangle,\langle\mathrm{i}\rangle,\langle\mathrm{big}\rangle$, $\langle$ small $>,\langle\mathrm{em}\rangle$, <strong $\rangle$, and $\langle\mathrm{tt}\rangle \ldots \ldots \ldots \ldots . .166$

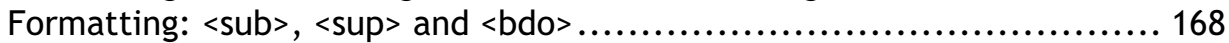

Formatting: $<$ ins $>$ and $<$ del $>$.......................................... 169

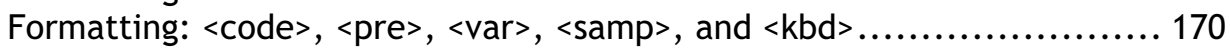

Checkpoint: Part 3 ....................................................... 171

Further Learning ................................................ 173

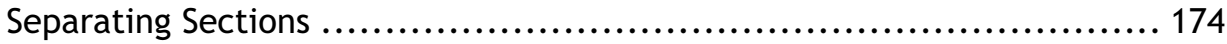

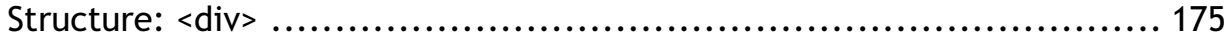

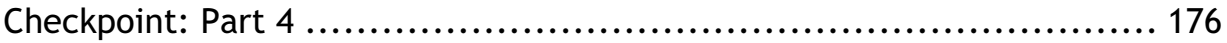

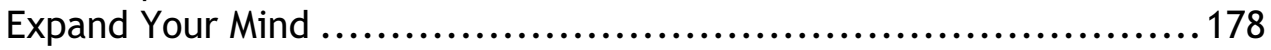

Inside Your Head...................................................... 179

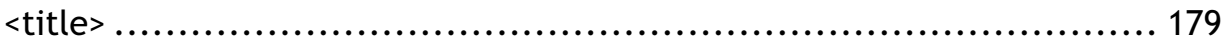

$<$ meta> .............................................................. 180

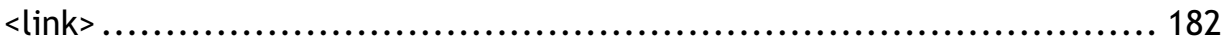

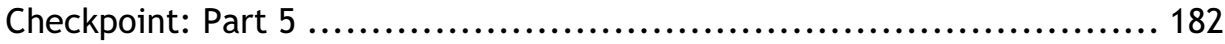

What Else Can You Do? ........................................... 184

Forms ................................................................. 184

Frames: <frameset>, <frame>, <noframes> and <iframe> ................... 190

The PVNK Approach .................................................. 191

Summary ...................................................... 192

Chapter 4: What About Web Hosting?..................................... 195

There's No Place Like Home........................................ 195

The Web Site Addresses ................................................ 196

Choosing a Domain Name .............................................. 199

Choose Your Landscape ...........................................209

What Is a Web Server? ................................................. 209

Beware the Villains!................................................ 212

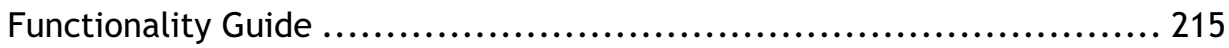

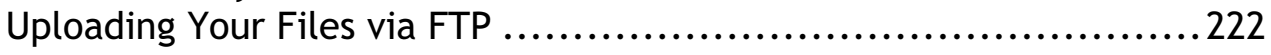




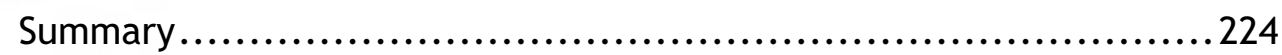

Chapter 5: How Can I Style My Website? ................................ 227

Back to Basics.................................................... 227

Under the Hood ..................................................... 228

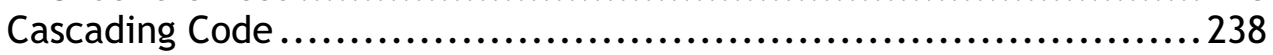

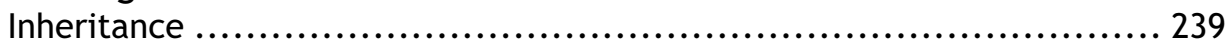

Specificity ........................................................ 242

Colors and Units ................................................... 244

Color Values .......................................................... 245

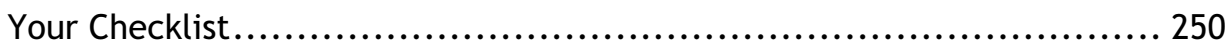

Getting StartED! ................................................ 251

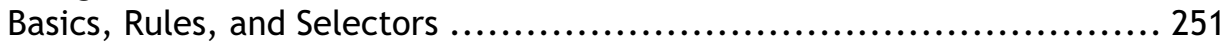

Super Selectors! ...................................................... 259

Targeting with Combinators .............................................. 263

Properties and Values ................................................ 266

Fonts and Text ..................................................... 267

Colors, Backgrounds, and Borders ...................................... 276

Choosing the Right Color ............................................... 282

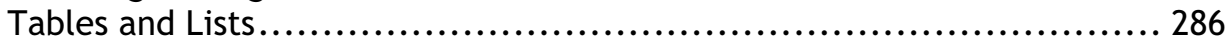

Using CSS for Design .................................................... 290

The CSS Box Model ...................................................... 296

Dimensions, Margins, and Padding ...................................... 301

Position, Visibility, and Behavior ........................................ 304

Summary........................................................... 309

Chapter 6: How Can I Use Images and Media? ........................... 313

Pushing Pixels..................................................... 313

Online Formats...................................................... 314

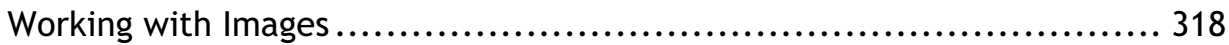

Mass Multimedia ..................................................... 329

Languages in Use ........................................................ 330

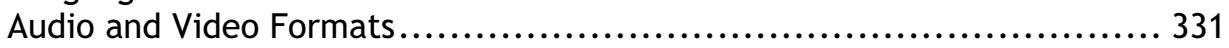

On-Demand Streaming ............................................... 334

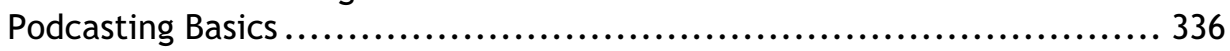

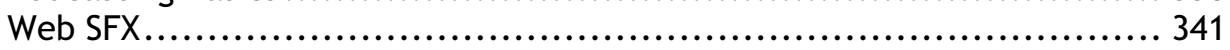

Getting More for Your Money ....................................... 344

Speed Tweaks ........................................................... 344

Summary ...................................................... 347

Chapter 7: What If Something Goes Wrong? ............................. 351

Where Did It All Go Wrong? ............................................ 351

The Browser Wars ..................................................... 352

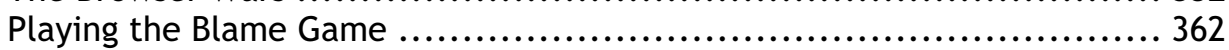

Conditions, Quirks, and Filters ...................................... 367

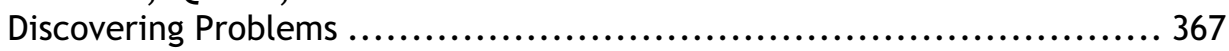




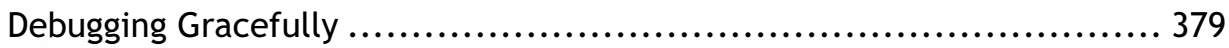

Prevention Is Better Than Cure .......................................... 390

Understanding 404 (Section Not Found) Errors ....................... 392

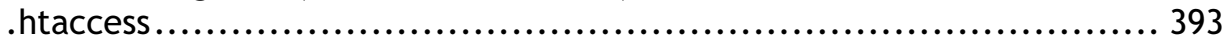

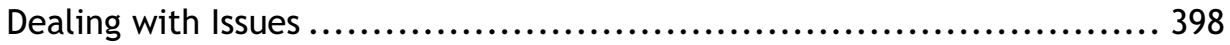

Maintaining Support .............................................. 401

Summary ........................................................ 404

Chapter 8: How Can I Add Interactivity? ................................. 407

Back to Basics................................................ 407

Under the Hood ................................................... 408

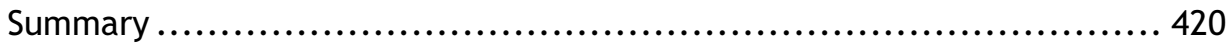

Client-Side Scripting ........................................... 420

Languages in Use ................................................. 421

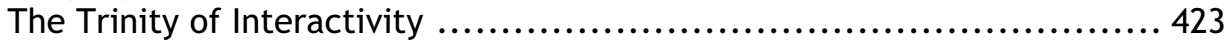

Scripting Semantics .............................................. 427

JavaScript Frameworks ............................................... 435

Bookmarklets........................................................ 436

Additional Resources................................................ 438

Server-Side Scripting ........................................... 438

There and Back Again .................................................. 439

Powerful Packages .................................................. 446

Head in the Clouds .................................................... 455

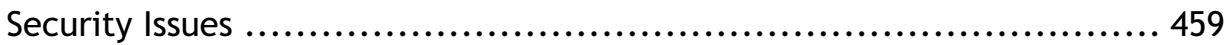

Summary ........................................................ 462

Chapter 9: How Can My Website Be Improved? ............................ 465

Accessibility with Agility ......................................... 465

What Is Accessibility? .............................................. 466

Assistive Devices....................................................... 469

Accessibility Issues ................................................ 473

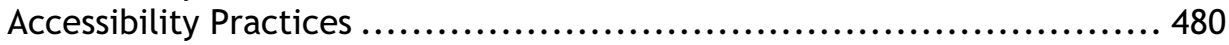

What Can Go Wrong? ................................................ 488

Writing an Accessibility Statement ................................... 491

Accessibility Standards ...........................................492

Accessibility Validation .............................................. 497

Experience Is Everything ........................................498

Design Theory ........................................................ 499

Usability Considerations ............................................... 502

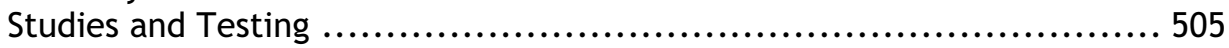

Mastering Microformats ............................................5509

Metadata Markup ..................................................... 510

Microformats ........................................................... 511

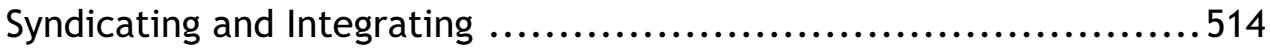

Generating Feeds ...................................................... 514 
Integrating Extensions .......................................... 522

Summary .................................................... 526

Chapter 10: How Can I Get More Visitors? ................................. 529

Search Engine Optimization ....................................... 529

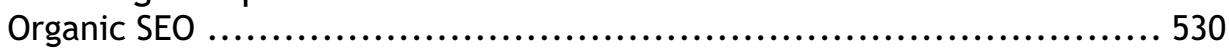

White Hat SEO ........................................................ 538

Black Hat SEO .................................................... 552

Mastering Marketing ................................................. 558

Advertising........................................................... 558

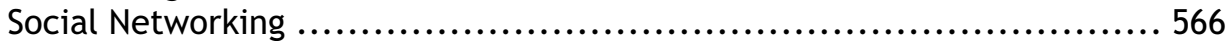

Selling Your Services................................................... 572

The Bizarre Bazaar ................................................ 573

Payment Systems ....................................................... 577

Self-Defense ........................................................... 582

Summary............................................................ 587

Appendix A: The Ten Commandments for Websites ................... 591

Follow the Specifications ......................................... 592

Think of Your End Users' Needs........................................ 592

Have Realistic Goals and Intentions ................................... 592

Have a Pragmatic Approach .......................................... 593

Think Outside the Box ................................................. 593

Know Your Subject Well............................................... 594

Crawl Before You Walk ............................................ 594

Interact with Your Customers ........................................ 594

Be an Efficient Manager ........................................... 595

Always Update Your Website ....................................... 595

Appendix B: Additional Materials ........................................ 597

Useful Websites ....................................................... 597

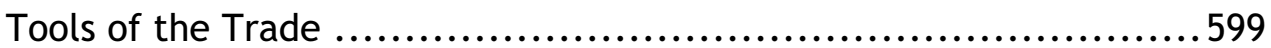

Website Editors ......................................................600

WYSIWYG Editors ................................................... 600

Source Code Editors / IDEs........................................... 602

Plain Text Editors .......................................................... 603

Useful Software.......................................................604

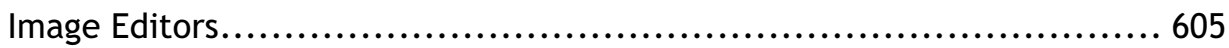

FTP Clients ........................................................ 606

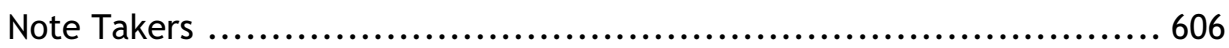

E-Mail Programs..................................................... 607

Word Processors ......................................................... 608

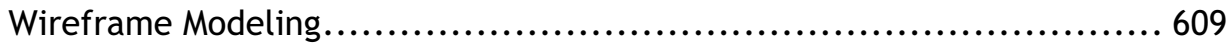

File Archivers........................................................... 611

Backup Utilities ................................................... 612 
Color Pickers 613

Flash Developers.

Firebug ...

Codeburner....

Web Developer Options

Firefox Accessibility Extension

ColorZilla 


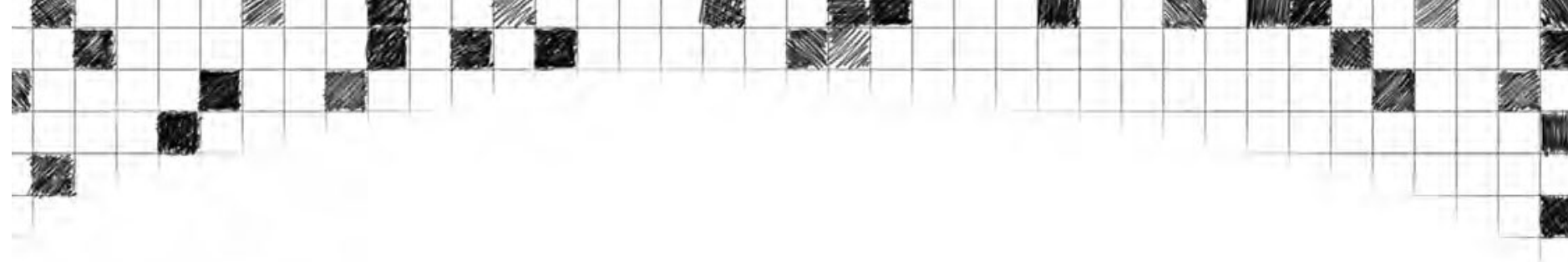

\section{About the TochnicoulliRevilewerie}

Kristian Besley is a Flash and web developer currently working in education and specializing in games/interactivity and dynamically driven content using Flash, PHP, and .NET (not all at the same time, obviously!). He also lectures in interactive media.

Kristian has produced freelance work for numerous clients including the BBC, Heinemann, and BBC Cymru. He has written a number of books for friends of ED, such as working on the Foundation Flash series, Flash MX Video (ISBN-13: 978-1-59059-172-7), Flash ActionScript for Flash 8 (ISBN-13: 978-1-59059-618-0), and Learn Design with Flash MX (ISBN-13: 978-1-59059-157-4). He was also a proud contributor to the amazing Flash Math Creativity books and has written for Computer Arts magazine.

Kristian currently resides with his family in Swansea, Wales and is a fluent Welsh speaker. 


\section{Acionowiledginenits}

Before we get started, it's only fair that I should give thanks to the many people who have given me support and assistance, or have just inspired me, on this journey of writing a book for those starting out in building websites.

First, my thanks have to go out to the team at Apress and friends of ED, who gave me the opportunity to get published. It's been a real pleasure getting to know you all. Some of the names needing a shout out here are Ben-Renow Clarke (for giving me the opportunity and tirelessly working to get this book released), Kelly Moritz (who, like Ben, gave me hours of useful Skype and e-mail assistance when it was needed most), and Kristian Besley (who gave his wise advice to help make this a better book). Also praise needs to be given to Patrick Meader and Heather Lang, who took my scary grammatical skills and helped this book evolve into something worthy of reading!

Next, I need to give a shout out to my friends on the SitePoint forums. Without your longstanding presence of helping others with technical questions about web design and development, the Web would be a much darker place. Giving your free time to help anyone who joins the community really does make a difference.

I also need to shout out to all my friends on the koach.com network and elsewhere (like MSN Messenger) who have put up with (or are secretly cheering at) my absence for the months I spent writing this book.

Finally, I need to give thanks to anyone who decided to give this book a read. It covers a wide range of subjects, so I hope that no matter your interests, some information in it will help you better understand the web design process. If this book helps a single person, it will have been worth the effort I put into writing it. 



\section{Book Conventions}

This book is a great resource if you are building a website for the first time, and it uses some cool methods to structure the content to make things easier to read. The following conventions have been used to try to break down some of the stuffy subjects into easy-to-swallow segments. The book also makes use of screenshots and examples throughout to help you see how technologies interact, visualize your web designs easier, and generally show you how to organize all the bits and pieces in your design without leaving you puzzled. As a general rule, when you see "Try It Yourself" sections, you should take the opportunity to pause reading and follow the instructions to achieve a goal that will assist you in your development process. These sections provide important exercises for this book. When you find a "See for Yourself" section, you can look at the example, play around with it, or even adapt the provided code or information when making your own website. In short, these are the examples in this book:

- $\quad$ Try It Yourself: Step-by-step tutorials you should follow to achieve a goal

- See for Yourself: Examples that you can use or adapt for your website

The following sidebars are also included for your use:

- LinkED: Useful website addresses related to the subject

- ExplainED: A basic explanation for something being talked about

- NotED: Details that more-advanced readers may find interesting

And here are some other useful sections you'll find:

- Tips and Tricks: These sections explain things to take into account that could affect your website.

- Questions and Answers: These sections offer simple answers to questions you may have.

- Chapter Checklist: Measure your progress by marking off your achievements.

You are about to embark on a journey of learning, creativity, and hands-on skills that will test your mind to the limits. At times, you might wonder if you can swallow all of the information available, but just keep picturing the finish line and remember that learning never has an expiration date. Everyone has a own unique way of learning, and you can decide for yourself when you feel that you are ready to take in some new information. Before we get into the meaty 
aspects of web design (that is, creating something), the following section has been included to give you a crash course in understanding how the Web works, in case you don't already know.

\section{Understanding Some Basics of the Web}

Can you picture a world without the Internet? There would be no access to the mighty Google, no information stored inside Wikipedia, and no ability to instantly contact people through e-mail, social networking, and instant messaging. We, as members of a modern society, depend on the Internet for everything from making new friends from all over the world right up to delivering high-quality savings on the kinds of goods we once bought at a premium in brick-and-mortar stores. Some businesses are entirely run through the Internet without having a physical presence! When producing websites, you should have a basic understanding of the history and technology that goes into keeping the Web running to give you perspective on the bigger picture.

\section{What Is the Internet?}

The Internet and the World Wide Web are different things. The Internet is made up of hardware (think of your computer) and has lots of cables streaming out of the back leading in different directions keeping in constant communication with other machines that are hooked up to the Web. The Internet supports everything that you choose to run on it. The World Wide Web, on the other hand, is the software and goes through a series of processes to send and receive information, which is controlled by the behavior of the people who use it. Because we are going to build a website, rather than focus on all the behind-the-scenes stuff (which the majority of us leave to the people who keep our websites running), we will focus entirely on the World Wide Web.

\section{ExplainE}

For future reference, the World Wide Web may be referred to as the Web or WWW, which is where you get the www at the start of a website address.

Information is transferred around the Web using a variety of methods; each method of transferring information has its own specific purpose and is commonly referred to as a protocol. You don't need to know the technical lingo, but you already make use of these protocols on a regular basis (see Figure 1). Whenever you go to your favorite website, you make use of the 
Hypertext Transfer Protocol (HTTP), which basically means that you request information and a website sends it to you. If you upload your design onto the Web, you use the File Transfer Protocol (FTP), which lets you take stuff from your computer and place it online. Finally, if you buy something off the Web, the website will keep everything secret from prying eyes using HTTPS (the " $\mathrm{S}$ " stands for "secure").

When these are in use you can see them working their magic. If you have a web browser window open, just take a look at the address bar. You will notice (perhaps for the first time) that before the ://www, which shows your website address, there will be an acronym like http, https, or ftp listed before it, which indicates the protocol your web browser is using. Fairly simple, right?

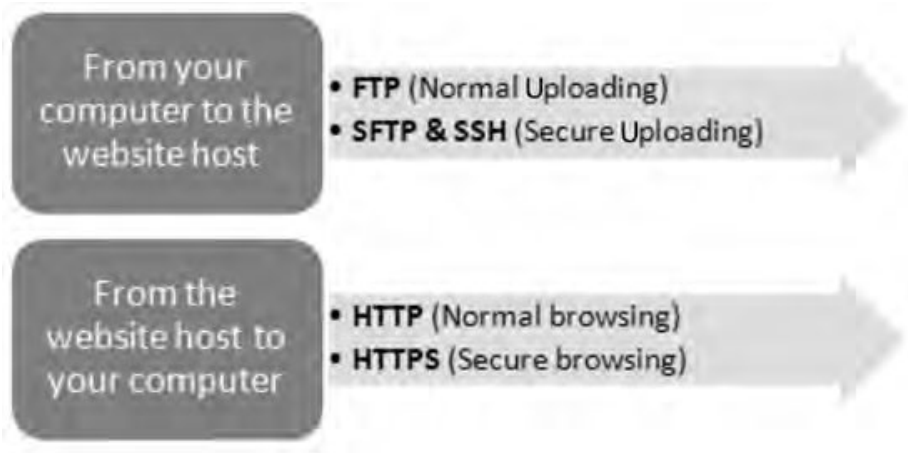

Figure 1. This diagram explains the direction in which several protocols send information.

The place where your site will be hosted is, not surprisingly, called the host or the server (that is, the machine that serves information to your computer). Likewise, the computer that accesses the website through a web browser is called a client (like being a customer of the Internet). Information is sent, upon request, down your telephone line into your computer so that the web browser can look at it and start making use of it. Figure 2 how the computers interact with each other, much like two people having a conversation on a telephone; information is exchanged by your computer and the place where the stuff you want to look at is hosted. Things get really interesting (as we will look at next) when browsers spice up the conversation and make elements appear on your screen! 

today. There are many different kinds of web browsers (as discussed later in the book), you will find that the vast majority of your visitors will make use of one of desktop browsers named previously or a mobile browser on a cell phones or portable device.

Browsers take text documents that have been specially formatted for the Web and use that formatting information to decide how the page will appear visually. Here's a simple way to view this in action: Go to any website of your choice (just pick one at random). Right-click the screen when the page loads, and select the View Source menu option to see what is going on behind the scenes (see Figure 3). What you will see is a page of code.

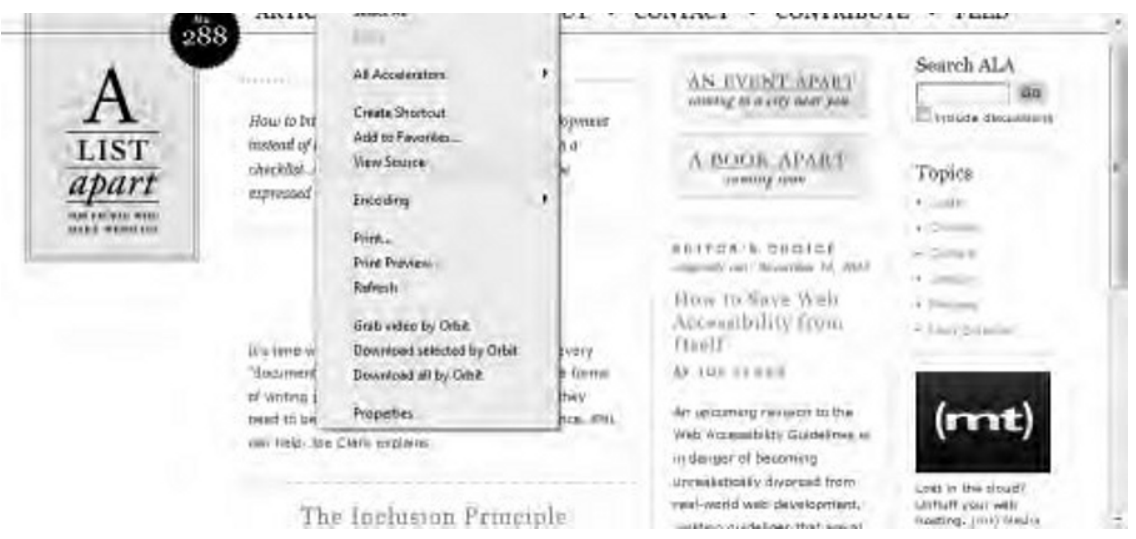

Figure 3. Right-click a website, and select View Source, so you can see how the document is formatted!

Code is defined as the elements of the document that explain and decide how the page should appear. When we talk about web development, most code is referred to as markup because it marks elements of a page to have special formatting applied to them. When you first look inside a website's source code, you will probably think it looks pretty alien and confusing (see Figure 4). With all those weird bits and pieces placed throughout the document, the code probably makes no sense to you at all. However, when you get used to seeing this information, you will notice that everything has a purpose (which we will discuss later).

Now that you know what a website is and how everything gets shuffled between your computer, the browser, and the place that holds the documents online, we will look at what exactly makes a perfect website. After all, you don't want to make your site look horrible; you want it to look exactly how you may have pictured it in your imagination! 


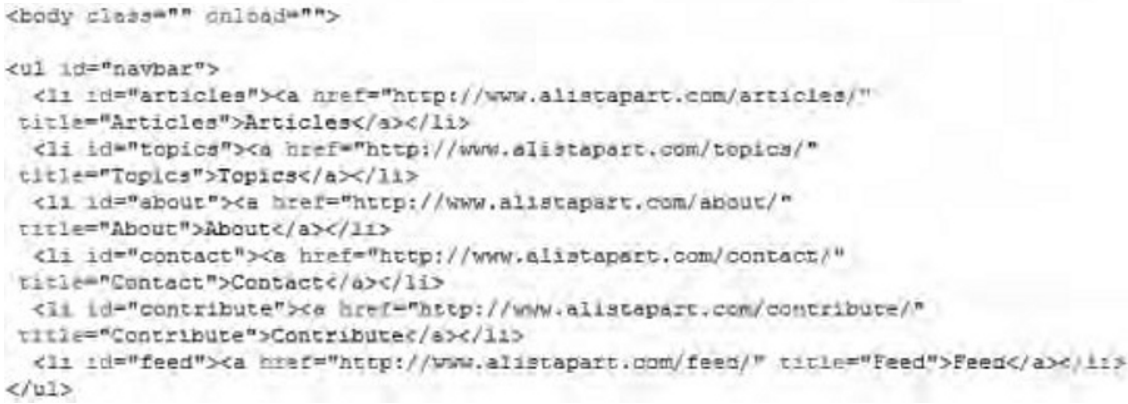

Figure 4. This code may look confusing, but it explains to the browser how everything is laid out.

\section{The Ten-Step Guide to Zen Creativity}

The steps involved in creating what could, perhaps, be the ideal homepage are quite simple and straightforward. However, creating websites is a skillful and artistic process because it takes practice, time, and effort. You need to not only learn to adopt these skills but to be able to implement them in such a way that your website will have longevity over the years to come. To help you understand the book's method of teaching, I have devised what I call the tenstep guide to Zen creativity, a series of ten words written in order that define the very essence of what producing the perfect website requires. The questions provided for each element in the "Try It Yourself" sections are to help look at other people's websites (and eventually your own) to see where they went wrong or where they did well. If you want to apply these steps to your own website, you can refer to this section once yours is completed.

The ten steps are as follows:

1. Capability

2. Productivity

3. Simplicity

4. Desirability

5. Functionality

6. Compatibility

7. Flexibility

8. Accessibility

9. Usability

10. Expandability 
The following poem is easy way to remember them:

I'm capable of being productive, simple, and desirable too.

I function on multiple levels, compatible all the way through.

I can flex to my users demands, being accessed and used just right.

And when I'm updated and expanded, I make for a very good site!

\section{Capability}

What makes an individual capable of creating a website, or what makes a browser capable of showing that website correctly and easily? The answer is as simple: standards, rules, and history. Without a basic understanding of what goes into making a website, neither the creator of the site nor the creator of the browser can ever hope to make things look and feel as intended. The pinnacle of most sciences is experimentation and education, and producing for the Web is no exception to this rule. By learning about a wide range of subjects, you gain a very powerful insight into the way things work, what mistakes have been made in the past, and how to avoid falling into those traps. An endless wealth of knowledge is available to someone wishing to make a website, and understanding the standards that exist will allow you to become more experienced as an individual and able to match the professionals.

\section{Try It Yourself: Checking for Capability}

- Do you understand how the web browser makes a site appear the way it does?

- Have you learned enough about the different languages to decide which to use?

- Are you keeping your knowledge up to date beyond just what this book offers?

- Do you feel comfortable at the end of each chapter with what you have learned?

- Are you aware that you can get support for most of your questions online for free?

\section{Productivity}

The last things anyone hoping to build a website wants to come across are sudden lacks of ideas or motivation to put plans into action. Many people would like to just jump straight into the process and get down to making a website, 
but problems soon arise if they do not know where they want to go with their projects. To give you the best possible start before you actually get down to coding, a few chapters in this book talk about what you need to do before you physically start putting the website together. You may want to get busy right away, but knowing what you are building is important before you put your site together. This book takes that approach because you do not want to end up with a "build now, think later" philosophy that come back to bite you when you try to get your ideas into the design. Nothing beats having a good plan of action that you can use as a reference (or starting) point in your project. It will give you the added benefit that you can track your progress and reduce the chances you will forget something important. After all, what kind of architect would build a house without knowing how many rooms or floors the building requires?

\section{Try It Yourself: Checking for Productivity}

- Have you decided what kind of site you would like to build throughout this book?

- Are you aware of other websites that are competing against yours for visitors?

- Do you know and are you equipped to deal with your visitors' requirements?

- Have you spent any time considering how your want your site's pages laid out?

- What ideas do you have, and are they written down so you don't forget them?

\section{Simplicity}

Nobody likes mess, and nobody likes tasks that are overcomplicated or frustrating. Simplicity is the key to avoiding trouble when building a website. Now, I do not mean that your designs themselves should be minimalistic, far from it. When you start building, your intention should be to keep to the bare minimum the amount of effort you require to achieve the effect you want. For example, if you have two equal designs and one is half the size and requires less effort to produce, why would you want to do more work and more maintenance for the website than absolutely necessary? Later in this book, you will learn how to manage everything you build, and by doing so, you may actually avoid some of the more annoying quirks that can occur when large amounts your design and the stuff that goes into making it become hard to maintain. 


\section{Try It Yourself: Checking for Simplicity}

- Do you know how to reduce errors on your site by validating your pages?

- Can you decide which languages for the Web will meet your website's needs?

- $\quad$ Are you able to separate the layers of your design to improve maintainability?

- Do you know which elements of a language will best explain its contents?

- Do you understand enough about your chosen languages to do a good job?

\section{Desirability}

Everyone (secretly) loves a beautiful website. It is entirely possible to go over the top trying to make your design outstandingly sleek, but even some minimalistic websites can achieve the element of beauty that will make other people jealous. Getting your website looking good is a key factor, but the look certainly should not be the only reason people visit your site.

The key to any website's success is its inner value, made up of services, content, and products you offer through it. After all, the majority of people do not visit a site with the intention of ranking it on "Hot or Not." They visit your website to learn more about what you have to offer them and read the contents of your website that enticed them there in the first place.

You may, therefore, ask why desirability is so important if it cannot attract visitors. Well, the simple answer is that a well-structured and good-looking design may help increase the enjoyment someone gets out of viewing and browsing your site, which can be essential to gaining regular visitors for the websites you build. However, you should be extremely careful to remember that you cannot please everybody. You should try as hard as you can to make your website the kind of place where people will feel at home, but there will always be a small group of people who just cannot be satisfied. Sometimes, you just have to let go of the criticism you get to avoid being sucked in by obscure requests and feature ideas that might drive away other visitors. After all, some individuals (and potential visitors) unfortunately enjoy being rude to website owners. 


\section{Try It Yourself: Checking for Desirability}

- Does your website look pretty to you, your friends, and people who visit?

- Have you received any complements about how good your design looks?

- $\quad$ Are you always making minor tweaks to ensure things stay looking fresh?

- Do you feel there are areas where your design could improve over time?

- Have you given any thought to how your site looks to people who are color blind?

\section{Functionality}

Most websites fall into one of two categories: static sites contain no flashy interactive behavior, and dynamic sites let visitors do more than just click and be sent to a page by offering special effects, customized content, and much more. Static websites serve their purpose as a baseline for what visitors should expect when taking their first trips to your website (and we will start off building a static website). However, you should not underestimate the value of extending the functionality of your website when you are given the opportunity, such as in the discussion of scripting basics later in this book.

Functionality can come in many forms and be implemented through many technologies (as you will find out later on in this book), but remember that functionality must fit the purpose of the website. Any additions to the interface that will interfere with the user experience or draw attention away from the purpose of your site should be left out of the final design. The key to being functional is to be consistent, so you should use your best judgment to decide what should be put in or left out, which means you will spend a fair amount of time making decisions.

\section{Try It Yourself: Checking for Functionality}

- Does your website actually need interactive elements like a member system?

- What kind of interactivity do you think would be really useful to your visitors?

- Have you thought about what might happen if functionality is unavailable?

- $\quad$ Are you willing to use existing software to simplify adding site functionality? 
- What methods does your website provide to let visitors get in touch with you?

\section{Compatibility}

Don't you just hate it when things start breaking without notice? I certainly do! When building your website, you will find that many factors can influence how your design comes out. Unfortunately, no easy fix can resolve the problems that different browsers, users, and needs will bring you in the long run, but you can learn to cope with problems by minimizing the chances of anything going wrong in the first place. That way, when something does go wrong, you can clean up the mess with as little hassle as possible. Cleaning up messes is the one step that most people would love to be able to do without, but the advantage of ensuring compatibility does mean you will find yourself able to better appreciate your finished website. More importantly, you will be able to deal with potential problems that may occur in the future with minimum effort.

\section{Try It Yourself: Checking for Compatibility}

- What happens when someone encounters an error on one of your pages?

- Does your website work on browsers like Firefox, Chrome, Safari, and Opera?

- $\quad$ Are you aware of the browser wars and how they affect building websites?

- $\quad$ Are all of your website's pages written correctly, and do they remain free of errors?

Do you know how to check, fix, and resolve any problems with your website?

\section{Flexibility}

This step in the process does have a lot in common with the previous one (compatibility), but some genuine differences should be taken into consideration. To define flexibility, the important thing is to simply ask yourself the question, "Do I feel lucky?" It may be cliché, but the question is a valid one. Flexibility in every sense of the word defines the website's ability to degrade with grace. Degrading gracefully means that if a certain technology is not available, rather than all of your hard work falling apart in front of your users' eyes or simply locking out those users, the site simply stubs its toe, grumbles a little, and carries on. Think of the process as giving your website and visitors a bit of dignity: the site may not display all the frills and 
excitement of the full thing and may take a less-picturesque route, but the important thing is that it continues to work!

\section{Try It Yourself: Checking for Flexibility}

- Have you ensured that plug-in reliant elements, like Flash animations, have alternatives?

- If style, scripting, or images are disabled, will your website still work properly?

- Does your website take into account people who use older browser versions?

- What happens to your website if someone looks at your site on a cell phone?

Can anyone using your website find any problems with the way it works?

\section{Accessibility}

The perfect website is hard to achieve, but the perfect visitor is impossible to find partly because everyone is different (in every respect of the word). Users have different requirements, needs, expectations, and abilities. All of this adds up to a complex situation that many people feel uncomfortable trying to address. The process of making your site accessible deals explicitly with taking care of your visitors who may have some impairment that could hinder their ability to browse your website. As you will find out later in this book, it's shocking just how many people are affected by these issues. When creating a website, there are so many things to take into account that it can make your head spin, but with a little practice and some understanding of what is relevant, you can make your site easy to use for almost anybody.

\section{Try It Yourself: Checking for Accessibility}

- Are you aware of the various types of disabilities that affect users of your website?

- What steps have you taken so disabled people can browse your site?

- Do you know anyone with a disability who may be able to test your site?

- Is there a method where people can get in touch with any issues they find?

- Have you checked the site does not use frames or other damaging features? 


\section{Usability}

When you visit websites, do you sometimes wonder why their creators made them so difficult to use? This concern has existed for many years and plagues the World Wide Web to this very day. Usability is an incredibly important step to take in your learning experience. Every individual expects something different from an experience, but you need to consider what will be most convenient to the largest majority of your visitors. Understanding how people make decisions and learning about conventions will allow you to be empathetic toward the people who you are trying to attract to your website and hopefully provide a website that has common and recognizable functions so people can navigate effectively.

The key to effective usability is to make everything appear where people expect it to appear and always use the terminology that people expect. For example, you would not call a contacts page a "communication resource center"-well, you wouldn't if you wanted people to actually contact you. People need to be able to use as little brainpower as possible, because splitsecond decisions determine whether someone will stay on or leave your site.

\section{Try It Yourself: Checking for Usability}

- Is your website easy to navigate? Can users quickly find relevant content or features?

- Have you ensured the design does not interfere with usability?

- Do you provide your visitors with multiple ways of navigating your website?

- Exactly how (upon reflection) do you think the website could be easier to use?

- Have you conducted a usability study to see if there are any navigation issues?

\section{Expandability}

Finishing the design and coding will not be the end of the process. Your website will be an ongoing process of adding new content, making new sections, and trying to get as many new visitors as possible. The success of a website is defined literally by the amount of people who enjoy visiting your website on a consistent basis, and therefore you are always in a battle against your fellow competitors to get more people looking at what you offer and making them want to visit your website instead. Expansion, therefore, comes in two forms: The first is to improve both the design and content of your website on a regular basis fixing any bugs and adding new functionality all of the time. The second form covers the art of marketing and 
search engine optimization, which deals with not only expanding your sites focus but also the amount of visitors you get, especially when a website with no visitors is pretty much considered nonexistent!

\section{Try It Yourself: Checking for Expandability}

- Are you aware of social networking and ways you can market your website?

- Does your website appear in search engines with a moderately high position?

- What plans do you have for the future to improve the website you have made?

- Have you received any feedback about users' wishes for future versions of the site?

- Are there any other ways you could market your website to get more visitors?

\section{ExplainE E}

Remember that these questions are only intended to get you thinking about completed websites. You are making your very first website, so these questions will be really useful to consider after the site is complete, especially if you intend on revisiting any parts of the book to see if you missed anything useful.

\section{Summary}

This ends my quick overview of the elements that go into making an ideal website. You will learn the specifics of these steps throughout this book, but the overview you have just read can act as a measuring stick for the principles you should keep trying to apply as best as you can when you begin coding. By answering these checklist questions as you go through the process of building your website, you should be able to rate your website to see how effective and how close to possible perfection it really is! Therefore, you may want to return to this section at the end of your website creation process to see if there are any areas you could improve on in the future, as these questions should certainly help you see if you put everything into practice effectively.

Are you ready to start building your very first website? If the answer is yes, let's get started! 